\title{
Limited predictive value of pre-surgical level of functioning for functioning at 3 and 12 months after TKA
}

\author{
Danielle D. P. Berghmans ${ }^{1,2,5,6} \cdot$ Antoine F. Lenssen ${ }^{1,2,5,6} \cdot$ Pieter J. Emans ${ }^{2,3} \cdot$ Lodewijk W. van Rhijn ${ }^{2,3,5,6}$. \\ Rob A. de Bie $4,5,6$
}

Received: 24 April 2018 / Accepted: 9 November 2018 / Published online: 28 November 2018

(c) The Author(s) 2018

\begin{abstract}
Purpose A total knee arthroplasty (TKA) is a cost-effective option to relieve pain and improve knee function in patients suffering from osteoarthritis. However, results differ among patients. The predictive value of pre-surgically assessed factors on the level of functioning after 3 and 12 months was investigated in this study.

Methods This study used an inception cohort design and a follow-up of 12 months. One hundred and fifty patients who were to receive a TKA were assessed pre-surgically with an International Classification of Functioning, Disability and Health (ICF) core assessment set: Knee Society Score (KSS), Western Ontario and McMaster Universities Osteoarthritis Index (WOMAC), Short-Form 12 (SF12), Patient-Specific Function Scale (PSFS), range of motion (ROM), quadriceps and hamstring strength and gait parameters. The main outcome measure was WOMAC-Function at 3 and 12 months after surgery. Results Pre-surgical physical and mental health on the SF12 and functioning and stiffness on the WOMAC explained 23\% of the variance in the level of functioning 3 months after surgery. Pre-surgical knee function measured with the KSS-Knee, and functioning as assessed by WOMAC-Function explained $16 \%$ of the variance of the level of functioning 12 months after surgery.

Conclusions The results of this study show that better functioning before surgery, less knee stiffness and a better physical and mental health to some extent predict better functioning 3 months after surgery. This effect is less evident at 12 months. This study is clinically relevant since it provides benchmark data for health care providers who want to compare their individual patients.
\end{abstract}

Level of evidence II.

Keywords Osteoarthritis - Arthroplasty $\cdot$ Knee replacement $\cdot$ TKA

\begin{tabular}{ll} 
Abbreviations \\
ASA & American society of anaesthesiologists grade \\
BMI & Body Mass Index \\
KSS & Knee society score \\
NRS & Numeric Rating Scale \\
PSFS & Patient Specific Function Scale \\
ROM & Range of motion \\
SF12 & Short form 12 \\
TKA & Total knee arthroplasty \\
WOMAC & Western Ontario and McMaster Universities \\
& Osteoarthritis Index \\
WOMACF & Western Ontario and McMaster Universities \\
& Osteoarthritis Index Function Scale \\
& \\
\hline Danielle D. P. Berghmans \\
danielle.berghmans@mumc.nl \\
Extended author information available on the last page of the article
\end{tabular}

\section{Introduction}

Several studies have investigated the influence of pre-surgical predictors on functional status post surgery. They found that scores on post-surgical health status questionnaires concerning level of functioning or quality of life are influenced by demographic factors $[1,7,12,21]$ (age, sex, body composition), psychosocial factors, $[1,7,12,15,21]$ medical factors (e.g. previous surgeries, complications, comorbidities), $[7,11,15,21]$ baseline physical functioning, $[1,6,11,12$, $15,18,21]$ use of walking devices, [11] walking distance [11] and pre-surgical pain [6, 15, 18].

However, existing evidence remains suboptimal, which is partly due to differences in study designs, specifically differences in prediction time periods $[1,3,11,12,21]$, predictors $[6,7,11,12,15,18,21]$ and outcome variables $[1,12]$, as well as small study populations $[3,21]$. Low 
quality evidence was also reported in a systematic review by Harmelink and Zeegers et al. [8] of prognostic factors for pain, functioning and quality of life 1 year after TKA surgery. As far as we know, no study has combined selfperceived questionnaires with a wide range of physical tests in a large population. Furthermore, no other study has objectively measured gait parameters in an extensive group of patients and used it in a prediction model [19]. This information is clinically relevant to determine the overall status of a patient. Recently there has been a great deal of interest regarding the effect of improving pre-surgical status on the immediate post-surgical recovery [23]. In the present study, the relationship between pre-surgical functional parameters and functional ability in the longer term was examined. Large datasets regarding the pre- and post-surgical functional status of TKA patients are lacking, which makes our study unique. In addition, the large study sample enabled us to investigate the relationship between multiple parameters and the post-surgical functional status. Our hypothesis was that taking account of pre-surgical functional parameters and self-report questionnaires assessing the 'function' and 'disability' domains of the International Classification of Functioning, Disability and Health model (ICF) would make the prediction models more complete. This information could inform clinicians and patients in the pre-surgical process.

A prognostic cohort study was conducted to determine the predictive value of factors measured before surgery for the level of functioning (measured with the Western Ontario and McMaster Universities Osteoarthritis Index function scale [WOMACF]) 3 and 12 months after a TKA.

The hypothesis was that a combination of pre-surgical functions and demographic variables would predict the postsurgical level.

\section{Materials and methods}

The local medical ethics committee reviewed and approved the study (NL33015.068.10/METC 10-2-083). The rights of subjects were protected under the Declaration of Helsinki.

An inception cohort design was used to recruit all consecutive patients with end-stage osteoarthritis 1 day before surgery. All patients were assessed as described in the "Procedure" section, before surgery. The WOMAC was repeated at 3 and 12 months after surgery, during a personal follow-up contact.

\section{Patients}

One hundred and fifty consecutive patients with osteoarthritis of the knee scheduled for a TKA at the Maastricht University Medical Centre (MUMC+) were informed about the study in writing and verbally at least 1 week before the planned surgery. The day before their surgery, all patients to be included were contacted by the researcher, and written informed consent was obtained. Four patients were lost to follow-up in the first prediction model (up to 3 months), and two additional patients were lost to follow-up in the second model (up to 12 months).

Inclusion criteria were: Dutch-speaking patients aged between 18 and 80 years at the time of surgery, diagnosed with osteoarthritis of the knee for which primary TKA was indicated. Patients were excluded if they underwent a unicondylar knee arthroplasty, had a neurological problem influencing ambulation or had an immobile hip or ankle arthrodesis. In addition, severe comorbidities (including severe psychological comorbidities) were automatically excluded because all patients had to be eligible for surgery.

The study population consisted of 79 women and 71 men. Mean age was 64.7 years $( \pm 7.9)$. Table 4 (appendix) shows baseline values for all parameters. The number of patients differed somewhat between the measurement instruments, because of inability to test due to unavailability or malfunction of the assessment equipment, or due to patients' inability (only regarding the quadriceps and hamstrings isometric $30^{\circ}$ measurements, in patients whose ROM was limited).

\section{Surgery}

All operations were performed by two orthopaedic surgeons, both with extensive experience with the procedure and prosthesis. All patients received a cemented Scorpio or Scorpio NRG Knee System (Stryker, Kalamazoo, Michigan, USA). After a medial parapatellar approach, a bony referenced, tibia-first technique was used. A cemented patella component was placed in 21 patients and a tourniquet was only used during the cementation period of the prosthesis. A previous study reported no differences in ROM, functioning or quality of life between the two prostheses [17].

\section{Procedure}

After signing informed consent, patients were enrolled in the study. All assessments were performed by the research team at the hospital on the day before surgery. The WOMAC was reassessed after 3 and 12 months. Patients were not shown the answers they had given at baseline or at 3 months.

All factors of the function and disability level of the ICF Model were included. The WOMACF was chosen as a primary outcome measure, as this scale comprises a variety of activities that are important in daily life.

Health insurance is mandatory in the Netherlands, so there were no financial obstacles. Patients who were unable to return to their own homes after surgery had the option of going to a rehabilitation facility. 
After surgery, patients received per protocol physical therapy in the hospital phase, aimed at increasing functional independence. After patients had left the hospital, physical therapy was continued in a private practice setting and patients received therapy according to the Dutch guidelines on TKA [13].

\section{Measurements}

In addition to assessing the patients' demographic characteristics (age, sex, height and weight), the following measurements were performed by the physical therapy team, using a standardized protocol.

\section{Health status questionnaires}

The WOMAC is a self-administered disease-specific health questionnaire designed to measure functional ability of the osteoarthritic hip and knee. The WOMAC provides aggregate scores for each of 3 subscales: joint pain, joint stiffness and function. Together, they form the total WOMAC score. The WOMAC is a responsive instrument that yields reliable and valid measurements in a population of patients with hip and knee osteoarthritis and has been used extensively to evaluate this patient population [11]. The 5-point Likert version of the WOMAC was used in our study (scale 0 to 100 points, $100=$ best score). The baseline sub-scores were used as parameters in this study, while the function sub-score of the WOMAC at 3 and 12 months was used as the outcome measure.

The Patient Specific Function Scale (PSFS) is a questionnaire to record patients' perceptions of their disabilities [22]. Patients define their main complaints regarding activities and rate the difficulty of performance on an 11-point numerical rating scale (NRS) [22]. The PSFS is a reliable and responsive measure in this population [2].

The Knee Society Score (KSS) is a knee-joint specific questionnaire and consists of two parts: a knee score and a function score [9]. The KSS is a valid and responsive measure in a population of patients following TKA [16].

The Short Form 12 (SF12) is a generic multidimensional questionnaire measuring quality of life from patients' point of view. It is a short version of the SF36 and includes two components (physical and mental health), representing their respective domains. It is a valid, reliable and responsive measure in a general population [24].

\section{Physical performance test}

Muscle strength was assessed with a Biodex ${ }^{\circledR}$ System 3 Pro dynamometer, measuring isometric $\left(30^{\circ}\right.$ and $60^{\circ}$, in $\mathrm{Nm}, 3$ repetitions each) and isokinetic peak torques (velocities of $60^{\circ}$ and $180^{\circ}$ /second, in $\mathrm{Nm}, 5$ and 10 repetitions, respectively) of the quadriceps and hamstrings. The Biodex ${ }^{\circledR}$ is a reliable and valid instrument [4].
Range of motion (ROM) was measured with a long-arm goniometer according to Lenssen et al. [14] Extension and flexion were measured in supine position, with hyperextension recorded as positive values. Measuring ROM is reliable at group level in patients after a TKA [14].

The gait parameters were measured with the GAITRite ${ }^{\circledR}$ system, a highly valid and reliable tool for measuring gait parameters in patients undergoing a TKA [25]. An electronic walkway is connected to a computer via six pressure-activated sensor pads inserted in a roll-up carpet.

\section{Statistical analyses}

At the start of the study, a sample size calculation was performed. Based on the number of determinants and the pragmatic rule of thumb to include ten cases for each determinant under study, at least 120 cases would be needed to obtain sufficient power $(10 \times 12$ determinants $=120)$. Since some loss-to-follow-up was expected, the total number needed was 150 subjects.

All data were collected. Missing values were not substituted and drop-outs were not replaced. All analyses were performed with SPSS version 23 [5]. Means and standard deviations were calculated.

Univariate regression analysis was performed including WOMACF and all independent variables. Factors with a $p$-value $\leq 0.10$ were entered into the multivariate regression model, using the ENTER method according to Field [5]. Assumptions were checked by residual plots and statistics, and total WOMAC scores were not included as predictors because of possible collinearity. Two prediction models were constructed: one model to predict level of functioning as measured with the WOMACF at 3 months, and another for functioning at 12 months.

The following independent variables measured before surgery were used: (1) demographic variables (age, sex), (2) BMI, (3) PSFS, (4) SF12-Physical, (5) SF12-Mental, (6) quadriceps strength, (7) hamstrings strength, (8) gait parameters, (9) ROM, (10) WOMAC at baseline.

\section{Results}

The pre-surgical values of all parameters are provided in Appendix Table 4, giving means and 95\% confidence intervals. The average overall improvement on the dependent variable of this study, the WOMACF, was $39.3 \%$ after 3 months and $51.0 \%$ after 12 months (Table 1).

The results of the univariate regression analysis including pre-surgical parameters and the WOMACF are presented in Appendix Table 5, which only shows the parameters that were significant and retained for multivariate analysis. As mentioned in the Methods section, only parameters with a 
Table 1 Mean values of the WOMAC subscales at baseline and 3 and 12 months post TKA

\begin{tabular}{|c|c|c|c|c|c|c|c|c|c|}
\hline & \multicolumn{3}{|c|}{ Baseline } & \multicolumn{3}{|c|}{3 months } & \multicolumn{3}{|c|}{12 months } \\
\hline & $n$ & Mean & $95 \% \mathrm{CI}$ & $n$ & Mean & $95 \% \mathrm{CI}$ & $n$ & Mean & $95 \% \mathrm{CI}$ \\
\hline WOMAC-pain & 149 & 10.7 & $10.0-11.4$ & 146 & 16.0 & $15.3-16.7$ & 144 & 17.6 & $16.8-18.4$ \\
\hline WOMAC-stiffness & 149 & 4.1 & $3.8-4.4$ & 146 & 4.9 & $4.6-5.2$ & 144 & 5.8 & $5.5-6.1$ \\
\hline WOMAC-function & 149 & 39.0 & $36.9-41.1$ & 146 & 54.4 & $52.2-56.6$ & 144 & 58.2 & $56.0-60.4$ \\
\hline WOMAC-total & 149 & 54.1 & $51.4-56.8$ & 146 & 75.4 & $72.4-78.4$ & 144 & 81.7 & $78.6-84.8$ \\
\hline
\end{tabular}

$n$ number, $95 \%$ CI 95\% confidence interval
Table 2 Prediction model for level of functioning 3 months after TKA

\begin{tabular}{|c|c|c|c|c|c|}
\hline & $B$ & Std. error & $p$-value & $95 \%$ CI LB & $95 \%$ CI UB \\
\hline Constant & 143.40 & 58.10 & 0.01 & 28.52 & 258.28 \\
\hline SF12P & 0.27 & 0.16 & 0.10 & -0.05 & 0.58 \\
\hline SF12M & 0.27 & 0.10 & 0.01 & 0.08 & 0.47 \\
\hline WOMACS & -1.16 & 0.65 & 0.08 & -2.44 & 0.13 \\
\hline WOMACF & 0.44 & 0.11 & 0.00 & 0.22 & 0.66 \\
\hline
\end{tabular}

95\% CI LB 95\% confidence interval lower bound, 95\% CI UB 95\% confidence interval upper bound

Table 3 Prediction model for level of functioning 12 months after TKA

\begin{tabular}{lrllcc}
\hline & \multicolumn{1}{l}{$B$} & Std. error & $p$-value & $95 \%$ CI LB & $95 \%$ CI UB \\
\hline (Constant) & 57.07 & 5.91 & 0.00 & 45.38 & 68.76 \\
WOMACF & 0.36 & 0.09 & 0.00 & 0.18 & 0.53 \\
KSSK & 0.12 & 0.07 & 0.09 & -0.02 & 0.25 \\
\hline
\end{tabular}

Std. Error standard Error, 95\% CI LB 95\% confidence interval lower bound, $95 \%$ CI UB 95\% confidence interval upper bound

significance level $\leq 0.10$ were included in the multivariate regression analysis. Since multiple parameters were significant for WOMACF at 3 and 12 months, several parameters were included in both models.

The final prediction model for level of functioning after 3 months, obtained from the multivariate regression analysis using the ENTER method, is presented in Table 2. This model had an $R^{2}$ of 0.228 .

Table 3 shows the final prediction model for functioning level after 12 months, after multivariate regression analysis with significant parameters from the univariate analysis and this final model had an $R^{2}$ of 0.163 .

\section{Discussion}

The most important finding of this study was that an extensive pre-surgical set of measurements including relevant parameters of the functions and disabilities domains of the
ICF model only had a limited predictive value for the level of functioning 3 and 12 months after TKA. The prediction model, which included SF12-Mental, SF12-Physical, WOMACS and WOMACF, explained $22.8 \%$ of the variance in the level of functioning at 3 months. This implies that the mental and physical status of the patients before surgery, combined with the degree of knee stiffness and the level of pre-surgical functioning predicted nearly a quarter of the level of functioning 3 months after surgery. This implies that better functioning before surgery, less knee stiffness and a better physical and mental health to some extent predict better functioning in the longer term.

The prediction model for 12 months after TKA surgery only included two predictors: WOMACF and KSSK, and explained $16.3 \%$ of the variance. In contrast to the model for 3 months, the patients' baseline mental status and overall physical status had no predictive value for the outcome after 12 months. Instead, only the pre-surgical level of functioning and the pre-surgical overall knee status predicted a mere sixth of the level of functioning 1 year after surgery. Both predictors are influenced by the timing of surgery; if the osteoarthritis worsens, the knee stiffens and muscle strength deteriorates, so the level of pre-surgical functioning is lower. After the TKA surgery there is then a higher risk that the level of functioning will still be lower after 1 year. Further research into the best timing for surgery would be helpful.

The constant factor in both our models was high, implying that the entire study sample showed good progress in terms of level of functioning. This supports the general concept of TKA as an effective procedure in osteoarthritis of the knee. The influence of the individual factors was small, as has also been reported by Jiang, Sanchez et al. [10] The small percentage of variance explained by both models is in line with what was reported in previous studies regarding the prediction of the level of functioning after a TKA using parameters measured before surgery. This means that a large part of the level of functioning could not be explained by physical predictors, neither in our study nor in those reported in the literature $[6$, $10,11,21,26]$. Therefore, the influence of other factors, not taken into account in this study, such as surgical techniques, complications or comorbidities, could explain another part of the variance and should be investigated in future studies [12]. 
In contrast with other reports, $[20,26]$ age and BMI were not significant factors predicting the level of functioning after surgery in this study. However, previous studies used different time periods or different performance tests as dependent variables. Other studies $[3,8,18]$ have reported findings in line with those in this study.

Our finding that mental status can have an effect on pain and functional status has also been reported by others [12, $15,20]$. However, in our study the influence of the mental status was only evident in the short term, unlike what was found in other studies $[15,20]$.

Several reports have described the influence of poor presurgical functioning on the level of functioning afterwards $[1,8,11,12,21]$. It was only the importance of the predictors which differed between the various studies.

In contrast to what has been reported in the literature [1], and contrary to our expectations, our study was unable to find a predictive value for the gait parameters. A reason could be our choice of the WOMAC as a dependent variable, whereas Bade et al. [1] used gait-related outcomes as dependent variables. They concluded that the pre-surgical performances on the Timed-Up-and-Go (TUG) or the Stair Climbing Test (SCT), or the distance walked in the 6-minwalk test (6MWT) predicted the post-surgical scores for the TUG, SCT and 6MWT, respectively. It seems that presurgical tests are mainly good at predicting their own postsurgical values.

Overall, the results of this study confirm the results of previous studies, in that pre-surgical functional status and knee status are important factors to predict the level of functioning afterwards, both in the short and longer term. Therefore, further research should investigate if improving pre-surgical factors might contribute to better outcomes in the long term.

The findings can be useful to identify patients with a poor prognosis. These patients may benefit most from the surgery, but extra attention must be paid to their physical recovery. The focus of further research could be on the effect of more, and more intensive, physical therapy on the prognosis of functional recovery.

Finally, this study has added information on the effectiveness of a TKA for the level of functioning after surgery. It could be helpful in the process of informing patients during the pre-surgical process, to give them some idea of the prognostic consequences, which is important in patient-centred care [15] and could reduce dissatisfaction after surgery. In addition, health care providers can use these results in their day-to-day clinical work to inform and benchmark their patients about their post-surgical rehabilitation, and encourage them to improve their presurgical functional status.

One limitation of our study is the lack of information about the specific physical therapy programmes attended by the participants, in terms of specific treatment content, attendance rates, duration, frequency and reasons for ending the therapy.

This study focused on general factors and on factors which might be influenced by physical therapy and the overall mental status, which enabled part of the variance to be explained. However, the specific influence of individual components of the mental or social status was not taken into account. Investigating a combination of these factors could improve a prediction model for the level of functioning after a TKA. Therefore, further research could focus on a combination of these factors and the pre-surgical level of functioning.

\section{Conclusions}

Overall, TKA is a successful form of surgery, in view of the considerable overall improvement in level of functioning. The predictive value of an extensive measurement set based on all important functions and disabilities of the ICF model proved to be limited.

Acknowledgements We would like to thank the following persons for their contributions to this study: Nick Coenen, Lotte van Delft, Simone Engels, Anja Großek, Aniek Heldens, Peter Hilgers, Elena Issigonis, Ramon Janssen, Jan Klerkx, Patrick Lebeck, Michael Leroy, Dennis Linden, Maarten Neuhaus, Laura Niggebrugge, Hugo van Nuland, Hannah Pallubinski, Ineke Salemans, Pia Stadler, Sanne Vijgen, Marwin Weber and Mandy Welters.

Author Contributions Study conception and design: DB, AL, RB. Acquisition of data: DB, AL. Analysis and interpretation of the data: DB, AL, RB, PE, LR. Drafting of the manuscript: DB. Critical revision: $\mathrm{AL}, \mathrm{RB}, \mathrm{PE}, \mathrm{LR}$

Funding This research did not receive any specific grant from funding agencies in the public, commercial, or not-for-profit sectors.

\section{Compliance with ethical standards}

Conflict of interest The authors declare that they have no competing interests.

Ethical approval The local medical ethics committee reviewed and approved the study (NL33015.068.10/METC 10-2-083). The rightsof subjects were protected under the Declaration of Helsinki.

Open Access This article is distributed under the terms of the Creative Commons Attribution 4.0 International License (http://creativeco mmons.org/licenses/by/4.0/), which permits unrestricted use, distribution, and reproduction in any medium, provided you give appropriate credit to the original author(s) and the source, provide a link to the Creative Commons license, and indicate if changes were made. 


\section{Appendix}

Tables 4 and 5 in appendix.

Table 4 Patient characteristics and baseline measurement

\begin{tabular}{|c|c|c|c|}
\hline & $n$ & Mean & $95 \% \mathrm{CI}$ \\
\hline Age (years) & 150 & 64.7 & $63.4-66.0$ \\
\hline Weight $(\mathrm{kg})$. Women & 79 & 84.6 & $81.2-88.0$ \\
\hline Weight $(\mathrm{kg})$. Men & 71 & 95.7 & $92.5-98.9$ \\
\hline Height (m). Women & 79 & 1.66 & $1.65-1.67$ \\
\hline Height (m). Men & 71 & 1.75 & $1.74-1.77$ \\
\hline BMI. Women & 79 & 30.7 & $29.5-31.9$ \\
\hline BMI. Men & 71 & 31.2 & $30.2-32.2$ \\
\hline PSFS1 & 150 & 1.9 & $1.6-1.9$ \\
\hline PSFS2 & 149 & 2.2 & $1.9-2.6$ \\
\hline PSFS3 & 138 & 2.6 & $1.6-2.3$ \\
\hline KSS-knee score & 150 & 52.5 & $49.8-55.1$ \\
\hline KSS-function score & 150 & 57.2 & $55.1-59.4$ \\
\hline SF12-physical & 146 & 33.5 & $32.2-34.8$ \\
\hline SF12-mental & 146 & 44.7 & $42.9-46.4$ \\
\hline $\begin{array}{l}\text { Quadriceps Isometric strength } 60^{\circ} \\
(\mathrm{Nm})\end{array}$ & 147 & 79.6 & $73.2-86.0$ \\
\hline $\begin{array}{l}\text { Quadriceps Isometric strength } 30^{\circ} \\
(\mathrm{Nm})\end{array}$ & 132 & 40.1 & $36.3-43.8$ \\
\hline $\begin{array}{l}\text { Quadriceps Isokinetic strength } 60 \% \mathrm{~s} \\
(\mathrm{Nm})\end{array}$ & 149 & 56.6 & $51.2-62.1$ \\
\hline $\begin{array}{l}\text { Quadriceps Isokinetic strength } 180 \% \mathrm{~s} \\
(\mathrm{Nm})\end{array}$ & 149 & 35.9 & $32.5-39.3$ \\
\hline $\begin{array}{l}\text { Hamstrings Isometric strength } 60^{\circ} \\
(\mathrm{Nm})\end{array}$ & 147 & 56.6 & $52.2-60.1$ \\
\hline $\begin{array}{l}\text { Hamstrings Isometric strength } 30^{\circ} \\
(\mathrm{Nm})\end{array}$ & 132 & 72.2 & $65.9-78.4$ \\
\hline $\begin{array}{l}\text { Hamstrings Isokinetic strength } 60 \% \mathrm{~s} \\
(\mathrm{Nm})\end{array}$ & 149 & 40.3 & $36.6-43.9$ \\
\hline $\begin{array}{l}\text { Hamstrings Isokinetic strength } 180^{\circ} / \mathrm{s} \\
(\mathrm{Nm})\end{array}$ & 149 & 30.8 & $28.0-33.6$ \\
\hline Flexion & 150 & 120.1 & $118.1-122.2$ \\
\hline Extension & 150 & -2.3 & -3.2 to -1.4 \\
\hline Walking speed $(\mathrm{cm} / \mathrm{s})$ & 145 & 98.9 & $95.0-102.7$ \\
\hline Step length surgical leg $(\mathrm{cm})$ & 145 & 57.6 & $55.7-59.5$ \\
\hline Step length healthy leg $(\mathrm{cm})$ & 145 & 58.0 & $56.4-59.7$ \\
\hline Stance surgical leg (\%GC) & 145 & 67.3 & $66.5-68.2$ \\
\hline Stance healthy leg (\%GC) & 145 & 65.8 & $65.0-66.7$ \\
\hline Swing surgical leg (\%GC) & 145 & 33.1 & $32.3-33.9$ \\
\hline Swing healthy leg (\%GC) & 145 & 34.7 & $34.0-35.4$ \\
\hline Single support surgical leg (\%GC) & 145 & 34.5 & $34.0-35.0$ \\
\hline Single support healthy leg (\%GC) & 145 & 32.9 & $32.2-33.5$ \\
\hline Double support surgical leg (\%GC) & 145 & 33.0 & $31.9-34.1$ \\
\hline Double support healthy leg (\%GC) & 145 & 33.2 & $32.2-34.3$ \\
\hline
\end{tabular}

$n$ number, $\% G C$ percentage of gait cycle
Table 5 Factors retained in multivariate regression analysis

\begin{tabular}{lll}
\hline & WOMAC3M & WOMAC12M \\
\hline WOMAC-pain & 0.00 & 0.00 \\
WOMAC-stiffness & 0.04 & 0.03 \\
WOMAC-function & 0.00 & 0.00 \\
PSFS3 & 0.03 & 0.09 \\
KSS-knee & $\mathrm{ns}$ & 0.00 \\
KSS-function & $\mathrm{ns}$ & 0.06 \\
SF12-physical & 0.00 & 0.00 \\
SF12-mental & 0.01 & 0.09 \\
Quadriceps isometric 60 & $\mathrm{~ns}$ & 0.05 \\
Hamstrings isokinetic 60 & $\mathrm{~ns}$ & 0.01 \\
Walking speed & $\mathrm{ns}$ & 0.02 \\
Step length surgical & 0.07 & 0.00 \\
Step length healthy & $\mathrm{ns}$ & 0.01 \\
Stance surgical & $\mathrm{ns}$ & 0.08 \\
Stance Healthy & $\mathrm{ns}$ & 0.07 \\
Single support surgical & 0.05 & 0.04 \\
Single support healthy & $\mathrm{ns}$ & 0.04 \\
Swing surgical & $\mathrm{ns}$ & 0.03 \\
Swing healthy & 0.06 & 0.03 \\
Double support surgical & $\mathrm{ns}$ & 0.09 \\
Double support healthy & $\mathrm{ns}$ & 0.06 \\
\hline
\end{tabular}

$r$ correlation coefficient, $n s$ non significant

\section{References}

1. Bade MJ, Wolfe P, Zeni JA, Stevens-Lapsley JE, Snyder-Mackler L (2012) Predicting poor physical performance after total knee arthroplasty. J Orthop Res 30:1805-1810

2. Berghmans DD, Lenssen AF, van Rhijn LW, de Bie RA (2015) Patient specific function scale: its reliability and responsiveness in patients undergoing a total knee arthroplasty. J Orthop Sports Phys Ther 45:1-22

3. Brown K, Kachelman J, Topp R, Quesada PM, Nyland J, Malkani A et al (2009) Predictors of functional task performance among patients scheduled for total knee arthroplasty. J Strength Cond Res 23:436-443

4. Drouin JM, Valovich-mcLeod TC, Shultz SJ, Gansneder BM, Perrin DH (2004) Reliability and validity of the Biodex system 3 pro isokinetic dynamometer velocity, torque and position measurements. Eur J Appl Physiol 91:22-29

5. Field AP (2009) Discovering statistics using SPSS. SAGE Publications Ltd, Thousand Oaks

6. Fortin PR, Clarke AE, Joseph L, Liang MH, Tanzer M, Ferland D et al (1999) Outcomes of total hip and knee replacement: preoperative functional status predicts outcomes at six months after surgery. Arthritis Rheum 42:1722-1728

7. Gandhi R, Dhotar H, Razak F, Tso P, Davey JR, Mahomed NN (2010) Predicting the longer term outcomes of total knee arthroplasty. Knee 17:15-18

8. Harmelink KE, Zeegers AV, Hullegie W, Hoogeboom TJ, Nijhuisvan der Sanden MW, Staal JB (2017) Are there prognostic factors for one-year outcome after total knee arthroplasty? A systematic review. J Arthroplast 32:3840-3853 
9. Insall JN, Dorr LD, Scott RD, Scott WN (1989) Rationale of the knee society clinical rating system. Clin Orthop Relat Res 248:13-14

10. Jiang Y, Sanchez-Santos MT, Judge AD, Murray DW, Arden NK (2016) Predictors of patient-reported pain and functional outcomes over 10 years after primary total knee arthroplasty: a prospective cohort study. J Arthroplast 32:92-100

11. Jones CA, Voaklander DC, Suarez-Alma ME (2003) Determinants of function after total knee arthroplasty. Phys Ther 83:696-706

12. Judge A, Arden NK, Cooper C, Javaid MK, Carr AJ, Field RE et al (2012) Predictors of outcomes of total knee replacement surgery. Rheumatology 51:1804-1813

13. KNGF (2018) KNGF-richtlijn Artrose heup-knie. Conservatieve, pre- en postoperatieve behandeling. https://www.fysionet-evide ncebased.nl/images/pdfs/richtlijnen/artrose_heup_knie_2018/ artrose_heup-knie_verantwoording_2018.pdf. Accessed 16 Sept 2018

14. Lenssen AF, van Dam EM, Crijns YH, Verhey M, Geesink RJ, van den Brandt PA et al (2007) Reproducibility of goniometric measurement of the knee in the in-hospital phase following total knee arthroplasty. BMC Musculoskelet Disord 8:83

15. Lingard EA, Katz JN, Wright EA, Sledge CB (2004) Predicting the outcome of total knee arthroplasty. J Bone Joint Surg Am $86: 2179-2186$

16. Lingard EA, Katz JN, Wright RJ, Wright EA, Sledge CB (2001) Validity and responsiveness of the Knee society clinical rating system in comparison with the SF-36 and WOMAC. J Bone Joint Surg Am 83-A:1856-1864

17. Lützner J, Hartmann A, Lützner C, Kirschner S (2014) Is range of motion after cruciate-retaining total knee arthroplasty influenced by prosthesis design? A prospective randomized trial. J Arthroplast 29:961-965

18. Papakostidou I, Dailiana ZH, Papapolychroniou T, Liaropoulos L, Zintzaras E, Karachalios TS et al (2012) Factors affecting the quality of life after total knee arthroplasties: a prospective study. BMC Musculoskelet Disord 13:116

19. Pua Y-H, Seah FJ-T, Clark RA, Poon CL-L, Tan JW-M, Chong H-C (2016) Development of a prediction model to estimate the risk of walking limitations in patients with total knee arthroplasty. J Rheumatol 43:419-426

20. Sharma L, Cahue S, Song J, Hayes K, Pai YC, Dunlop D (2003) Physical functioning over three years in knee osteoarthritis: role of psychosocial, local mechanical, and neuromuscular factors. Arthritis Care Rheum 48:3359-3370

21. Sharma L, Sinacore J, Daugherty C, Kuesis DT, Stulberg SD, Lewis $M$ et al (1996) Prognostic factors for functional outcome of total knee replacement: a prospective study. J Gerontol A Biol Sci Med Sci 51:M152-M157

22. Stratford $P$ (1995) Assessing disability and change on individual patients: a report of a patient specific measure. Physiotherap Can 47:258-263

23. Van Der Sluis G, Goldbohm RA, Bimmel R, Galindo Garre F, Elings J, Hoogeboom TJ, van Meeteren NLU (2015) What augmented physical activity and empowerment can bring to patients receiving total knee replacement: content, implementation, and comparative effectiveness of a new function-tailored care pathway in a routine care setting. BioMed Res Int 2015:745864. https://doi. org/10.1155/2015/745864

24. Ware JE Jr., Kosinski M, Keller SD (1996) A 12-Item Short-Form Health Survey: construction of scales and preliminary tests of reliability and validity. Med Care 34:220-233

25. Webster KE, Wittwer JE, Feller JA (2005) Validity of the GAITRite walkway system for the measurement of averaged and individual step parameters of gait. Gait Posture 22:317-321

26. Zeni JA Jr., Snyder-Mackler L (2010) Early postoperative measures predict 1- and 2-year outcomes after unilateral total knee arthroplasty: importance of contralateral limb strength. Phys Ther 90:43-54

\title{
Affiliations
}

\author{
Danielle D. P. Berghmans ${ }^{1,2,5,6} \cdot$ Antoine F. Lenssen ${ }^{1,2,5,6}$. Pieter J. Emans ${ }^{2,3} \cdot$ Lodewijk W. van Rhijn $^{2,3,5,6}$. \\ Rob A. de Bie ${ }^{4,5,6}$ \\ Antoine F. Lenssen \\ af.lenssen@mumc.nl \\ Pieter J. Emans \\ p.emans@mumc.nl \\ Lodewijk W. van Rhijn \\ 1.van.rhijn@mumc.nl \\ Rob A. de Bie \\ ra.debie@maastrichtuniversity.nl \\ 3 Department of Orthopedics, Maastricht University Medical \\ Center, Maastricht, The Netherlands \\ 4 Department of Epidemiology, Maastricht University, \\ Maastricht, The Netherlands \\ 5 Maastricht University, P.O. Box 616, 6200 MD Maastricht, \\ The Netherlands \\ 6 CAPHRI School for Public Health and Primary Care, \\ Maastricht University, Maastricht, The Netherlands
}

1 Department of Physical Therapy, Maastricht University

Medical Center, Maastricht, The Netherlands

2 MUMC+, 5800, 6202 AZ Maastricht, PO, The Netherlands 